\title{
Tradições confessionais chinesas - Análise introdutória
}

\section{Chinese confessional traditions - Introductory analysis}

DOI: $10.54018 /$ sssrv1n1-001

Recebimento dos originais: 06/01/2020 Aceitação para publicação: 31/01/2020

\section{Adelcio Machado dos Santos}

Doutor em Engenharia e Gestão do Conhecimento (UFSC). Pós-Doutor em Gestão do Conhecimento (UFSC). Docente e pesquisador nos Programas de Pós-Graduação "Stricto Sensu" em Desenvolvimento e Sociedade e em Educação da Uniarp.

Endereço: Rua Prof. Egídio Ferreira, ํo 271, Apto. 303 - 88090-699

Florianópolis (SC) Brasil.

E-mail: adelciomachado@gmail.com

\section{RESUMO}

Busca-se apoio nos textos de Armond (1999) para apresentar, à guisa de iniciação, as tradições confessionais chinesas. De acordo com o autor, a antiguidade da civilização chinesa vai além de 10 mil anos. O fundamento de sua religião nacional está nas obras de três sábios: Fo-hi, Lao-tsé e Kongtzeu (Confúcio), que viveram em épocas muito recuadas da história: o primeiro, como imperador, a partir de 3468 a.C.; o segundo 604 a.C. e o último 478 a.C. Mais tarde, com a introdução do Budismo, três passaram a ser as religiões da China: o Confucionismo, o Taoísmo e o Budismo (ARMOND, 1999).

Palavras-chave: Religiões; China; fundadores.

\section{ABSTRACT}

Support is sought in the texts of Armond (1999) to present, by way of initiation, the Chinese confessional traditions. According to the author, the antiquity of Chinese civilization goes beyond 10,000 years. The foundation of their national religion is in the works of three sages: Fo-hi, Lao-tzu and Kongtzeu (Confucius), who lived in very remote times of history: the first, as emperor, from $3468 \mathrm{BC}$; the second 604 $\mathrm{BC}$ and the last $478 \mathrm{BC}$ Later, with the introduction of Buddhism, three became the religions of China: Confucianism, Taoism and Buddhism (ARMOND, 1999).

Keywords: Religions; China; founders

\section{INTRODUÇÃO}

Para Oldstone-Moore (2007), as tradições religiosas da China repousam em dois princípios fundamentais: o cosmo é um lugar sagrado e todos os seus aspectos são inter-relacionados. $O$ objetivo principal da religião chinesa é 
sustentar essa santidade mantendo a harmonia entre os seres humanos e entre a humanidade e a natureza. Reflete-se isso nas tradições formais nativas do taoísmo e do confucionismo, da mesma forma, também como religião popular. $\mathrm{O}$ budismo, vindo da Índia, também se ajustou à perspectiva chinesa.

A religião chinesa tradicional se fundamenta num antigo entendimento de como funciona os Cosmos. De acordo com ele, tudo o que existe, inclusive o céu, a terra, os seres humanos e as divindades, é composto da mesma substância vital, ou qi (ch'i), O qi se manifesta fundamentalmente como duas forças complementares, o yin e o yang. Esses termos significam originalmente o lado sombrio (yin) e o lado ensolarado (yang) de uma montanha, mas bem cedo passaram a ser usados mais simbolicamente. Dessa maneira, o yin denota o que é escuro, úmido, inerte, turvo, frio, mole e feminino e, o yang complementar denota o que é claro, seco, crescente, luminoso, quente, duro e masculino. Todas as coisas têm yin e yang em proporções variáveis.

Oldstone-Moore (2007) acrescenta ainda que são expressas diversamente as principais tradições espirituais, com um ideal de harmonia cósmica aprimorada. A estrutura básica da tradição popular chinesa estava de pé no ano 1000. Ela inclui muitas práticas nativas antigas como o xamanismo, a adivinhação e a veneração dos ancestrais. Além disso, incorporou as idéias budistas de carma e renascimento e as suas cosmologias de céus e infernos, budas e bodisatvas, junto com a hierarquia taoísta de divindades.

Os confucionistas zombam das práticas religiosas populares, ao passo que o papel dos sacerdotes budistas e taoístas são conduzir rituais, e não explicar a doutrina para as massas. Eles são chamados para realizar determinadas cerimônias em templos dirigidos por organizações da vizinhança e não são permanentemente afiliados a templos da religião popular.

Esse autor destaca também que as religiões chinesas são frequentemente voltadas para o mundo e orientadas para a prática, e isso manifesta-se na tradição popular, que reflete as principais preocupações das Três Doutrinas, mas não tem um conjunto sistemático de crenças; concentra-se em melhorar esta vida

garantindo saúde, vida longa, prosperidade, harmonia doméstica, a continuidadeda linhagem familiar pelos filhos e a proteção contra calamidades. 


\section{DESENVOLVIMENTO}

Um relacionamento recíproco entre os vivos e os espíritos (ancestrais, divindades e fantasmas) é fundamental para a prática popular. Supõe-se que, se os homens desempenharem seu papel, o mundo espiritual responderá com a mesma moeda, concedendo benções - no caso de fantasmas - não fazendo nenhum mal.

Oldstone-Moore (2007) observa que nos últimos dois séculos, as tradições religiosas chinesas enfrentaram muitos desafios que originaram confrontos culturais e militares com o Ocidente. Intelectuais e governos tem considerado que elas são a causa da fraqueza chinesas e que se opõem à modernidade, se comparadas com a ciência e o racionalismo ocidentais. As políticas oficiais do regime comunista consolidam essa atitude, e é difícil avaliar a força atual da religião tradicional no continente. Porém, sempre que a pressão do governo relaxa, as práticas religiosas logo ressurgem.

Sobre os livros sagrados das tradições religiosas chinesas formais, Oldstone-Moore (2007), acrescenta que esses são formados por textos que não buscam representar o mundo do divino. Na verdade, os escritos confucionistas estão entre os textos antigos fundamentais que adquiriram status canônico para uma ou mais das principais tradições - ou mesmo todas elas.

Ainda que, até pouco tempo, apenas uma pequena porcentagem do povo chinês fosse alfabetizada, as idéias e os valores incorporados no cânone confucionista tinham tanta influência que são uma parte íntima de sua identidade cultural. Foram a base dos exames par ao serviço público chinês e, portanto, para o governo, durante dois milênios. Os funcionários eruditos que dirigiam o império aplicavam aos problemas de sua época lições recolhidas das obras do cânone.

A religião popular chinesa não conta com textos sagrados, embora diversos movimentos sectários tenham tido seus próprios escritos. O antigo Canções do sul (século IV a.C.) descreve o vôo xamânico e outras práticas e crenças que se conservaram na tradição popular. Com o advento da impressão no século VIII, textos baratos sobre moralidade derivados de diversas tradições religiosas tornaram-se bastante populares.

De acordo com Armond (1999), a obra de Fo-hi é pouco conhecida no ocidente, e dela só o livro chamado / Ching, contendo figuras, símbolos e 
trigramas, de significação obscura. Em todo seu reinado essa sábio empregou seu poder para espalhar o conhecimento das virtudes e dos dons morais entre o povo.

A importância dessa antiga teoria e prática de adivinhação expressa nessa obra é confucionista, o I Ching ou Livro das Mutações, foi composto ao longo de muitas centenas de anos a partir do início da dinastia Zhou. Embora seja parte do cânone confucionista, ele é importante para todas as religiões chinesas. Sua popularidade se deve em parte à especulação cosmológica, que encanta a elite, e, sobretudo a seu uso como manual de adivinhação, prática mantida até a contemporaneidade (OLDSTONE-MOORE, 2007).

O sistema de adivinhação dessa obra está baseada em combinações de oito trigramas, desenhos feitos com linhas quebradas e inteiras que representam as forças opostas e ao mesmo tempo complementares do yine yang. Os trigramas são associados em pares, em todas as combinações possíveis, formando um total de 64 hexagramas. Além de dar pareceres sobre os hexagramas e as linhas de que eles se compõem, o I Ching oferece comentários e explicações para auxiliar na interpretação dos resultados da adivinhação.

A tradição diz que Lao-tsé (ou Laozi), o lendário fundador do taoísmo nasceu em 604 depois de uma gestação e um nascimento milagrosos. Serviu na burocracia imperial e promoveu uma teoria de governo laissez-faire, porém, se desiludiu e se retirou para as montanhas. Entretanto, no meio do caminho um guarda do passo ocidental pediu-lhe que escrevesse seus ensinamentos. 0 resultado foi o texto fundamental do taoísmo, o Tao Te King. Existem duas tradições taoístas: o taoísmo "filosófico" e o taoísmo "religioso" (OLDSTONEMOORE, 2007).

Os textos fundamentais do taoísmo, o Tao Te King e o Zhuangzi, tiveram tanta influência na formação do ethos chinês quanto o cânone confucionista. Ensinam o caminho para encontrar a harmonia, porém, na busca do padrão e da ordem voltam-se para a força do tão, e não para uma antiga época de ouro. Como o Tão Te King, o Zhuangzi, que recebeu o nome de seu autor, defende a harmonia com a natureza. Deleita-se com suas formas sempre mutáveis e recusa os padrões de valor criados pelos homens e impostos sobre sua infinita variedade. Amorte e a vida são uma parte do processo da natureza, a ser abraçada com a mesma alegria e entusiasmo. O Zhuangzi conta histórias de pessoas e coisas 
curiosas e inclui vôos de fantasia (OLDSTONE-MOORE, 2007).

Sobre o taoísmo filosófico, representado por Lao-tsé e Zhuangzi (século IV a. C.), relaciona-se com a revelação e a obediência ao tao, a força e o padrão que estão por trás da ordem natural. Zhuangzi afirmava que a paz e a harmonia são o estado natural das coisas até os homens interferirem, e que é preciso ver a relatividade de todos os valores e pontos de vista.

Sobre o divino, o naturalismo místico do taoísmo filosófico não se relaciona com a virtude e a moralidade, mas com o movimento e a criação de todas as coisas de acordo com o tão, o "caminho" da natureza e do cosmo. Ele é a fonte eo padrão de todas as coisas que são formadas de material vital primitivo, ou qi, eque nele se dissolvem. Os taoístas expressam respeito à infinita sutileza e alcancedo tão, que permeia todas as coisas. O tão abarca todas as coisas; é silencioso, imperceptível e imparcial. Mas não é divino, e assim não pode ser cultuado comosão o Céu e as divindades (OLDSTONE-MOORE, 2007).

O ensinamento ético é importante no taoísmo, mas não necessariamente fundamental. O taoísmo filosófico enfatiza a procura da espontaneidade, da ação natural, ao passo que o centro do taoísmo religioso é a busca da longevidade e da imortalidade.

Por sua vez, o taoísmo religioso teve início no século II com movimentos como os "turbantes amarelos" e os "mestres celestiais" (também conhecido como o "Caminho dos Cinco Alqueires de Arroz"). Esses grupos associaram antigas práticas e crenças, como a busca da longa vida, a seus próprios escritos, divindades, rituais e, muito frequentemente, expectativas milenares, que o governo sentia como uma ameaça. Com o tempo, o taoísmo religioso criou um cânone de texto revelado, um panteão de divindades, sacerdotes, letrados e rituais estabelecidos (OLDSTONE-MOORE, 2007).

Lao-tsé deixou obra vasta, entretanto, apenas três de seus livros chegaramao conhecimento do homem moderno: o Tao, ou o Livro da Senda; o Te, o Livro da Virtude ou da Retidão e o Kang Ing, o Livro das Sanções ou das Reações concordantes. Cada livro é um código moral.

Armond (1997) diz que na primeira obra Lao-tsé diz: o sábio que está no céu, isto é, cujo espírito está desprendido da matéria, obteve uma vida longa e é lá no Alto que seus trabalhos merecem a grande paz. É calmo no sulco que para 
si traçou. Não procura tornar-se conhecido. Não perde o seu tempo em procurar a glória vã, em ofuscar aqueles que estão em torno dele. Seu caminho sobre para o Templo da Sabedoria; ele caminha com um passo igual; sempre avança e se eleva, descuidoso daquilo que não é para a assistência de seus irmãos e de sua própria perfeição. É, porquanto desenvolvendo em si mesmo as suas qualidades que o sábio é admitido para atingir a Senda.

No sentido popular ou religioso, o taoísmo propaga o culto dos ídolos, cada cidade tendo seu deus, o mesmo acontecendo com as casas, as montanhas, os rios, etc.

Oldstone-Moore (2007) acrescenta ainda que o taoísmo religioso apresenta uma vasta coleção de textos, de mais de mil obras, que continua crescendo. Esse cânone compreende tratados sobre temas diversos, inclusive rituais, alquimia, exorcismo, vida de pessoas nobres e revelações, consultados pelos sacerdotes eadeptos taoístas.

De acordo com Besen (2005), para os taoístas, a propriedade é um roubo, a injustiça social e as divisões em classe são um absurdo. O ideal seria uma sociedade coletiva em que se realizasse a cooperação espontânea, sem que houvesse um poder central dirigente: no máximo, seria suficiente um poder periférico, que exercesse pouco controle, e para as pequenas questões. $O$ Taoísmo, nessa visão de sociedade, propõe, de um lado, uma fuga no misticismo religioso, de outro, levou seus seguidores a se envolverem em revoltas populares. Como se pode perceber, mesmo nessa época remota Lao-Tsé transmitia conhecimentos de alto valor moral sendo, na realidade, um verdadeiro missionário.

Lao-tsé defende a busca do lugar de cada um na natureza e o aprendizado da prática do wu wei para alcançar uma vida harmoniosa. Numa linguagem resumida e mística, ele exalta a força do aparentemente fraco, como a água que gota a gota pode vencer a pedra. Paradoxalmente, Lao-tsé afirma que não se deve confiar apenas nas palavras e nos nomes, que são impedimentos para a percepção da natureza do tao. De acordo com a visão taoísta, as palavras são apenas um meio conveniente de indicar algo que está em constante fluxo e é inominável. 


\section{CONSIDERAÇÕES FINAIS}

Ainda com apoio do texto de Armond (1999) apresenta-se Confúcio como mestre do povo e ministro de alguns governos cujos cargos aceitava para poder exemplificar e oficializar os seus ensinos.

Oldstone-Moore (2007) acrescenta que o confucionismo, baseado nos ensinamentos de um sábio do século VI a. C., mestre Kong (Kong Fuzi, latinizado no ocidente como Confúcio), centra-se nas relações entre as pessoas e na criação de uma sociedade harmoniosa baseada na virtude. A virtude básica é o ren (benevolência, humanidade). Para Confúcio, a relação primordial é a dos pais com os filhos, sobretudo do pai com o filho, caracterizada por xiao, devoção filial. Com a manutenção desse vínculo, a família, a comunidade, o Estado e por fim o cosmo podem ser transformados.

Armond (1999) salienta que esse manifestou o equilíbrio que existe entre os poderes do céu e da terra, entre o homem e a natureza. Como fundamento ouimagem deste equilíbrio criou em sua época o culto da adoração do céu Tian; da adoração do imperador superior - Shangti - (poder criador); e da adoração dediferentes espécies de espíritos celestes, terrestres e humanos, sendo que estes últimos são os antepassados dos vivos. Nesse culto dos antepassados passou então a repousar grande parte da religião chinesa que tem, assim, um cunho nitidamente imortalista.

Na parte moral o confucionismo preconiza a vida virtuosa e obediente à hierarquia tanto terrestre como celeste, sendo indispensável à prática das virtudes.

É enfatizado ainda pelo confucionismo, os ensinamentos éticos, que são voltados para a criação de uma sociedade harmoniosa e de um Estado virtuoso, benevolente. Ambos podem ser alcançados se todos forem ponderados e sinceros e praticarem o ren, "humanidade" ou altruísmo. Confúcio acreditava que o ren consistia em tratar a todos com respeito e viver de acordo com a regra de ouro'.

A ética confucionista dá pouca atenção a recompensa ou punição fora deste mundo. Contudo, a virtude da devoção filial integrou-se bastante aos

\footnotetext{
${ }^{1}$ Regra de ouro: "Não faça com os outros o que não gostaria que lhe fizessem" (Os anacletos, $12,2)$.
} 
conceitos de salvação na tradição popular, principalmente no culto dos ancestrais.

Teoricamente, a fim se tornar um ancestral satisfeito e benevolente, em vez de um fantasma potencialmente maligno, uma pessoa precisa ter descendentes masculinos vivos, que realizem os sacrifícios necessários depois de sua morte (OLDSTONE-MOORE, 2007).

Confúcio afirmava que o governo precisa se basear na virtude e que todos os cidadãos devem estar atentos aos deveres de sua posição. Seu grande seguidor, Mêncio (Mengzi, 371-289 a. C.), elaborou os ensinamentos de Confúcio sobre a virtude humana e o bom governo, proclamando a bondade original da natureza humana e o direito das pessoas de se rebelar contra um mau governante (OLDSTONE-MOORE, 2007).

Zunzi (em atividade em c. 298-238 a. C.) que é considerado também como um grande pensador confucionista dos tempos antigos, ofereceu uma visão bem diferente da natureza humana. Afirmava que a humanidade era originalmente má e só tornava boa graças a leis rigorosas e punições duras. Suas opiniões foram levadas ao extremo pelos "legalistas", que formaram outra das Cem Escolas. Eles foram censurados na história chinesa devido a seu papel no brutal reinado do primeiro imperador de toda a China Qin Shihuangdi (221-209 a.C.), famoso por queimar livros em massa e por executar eruditos confucionistas (OLDSTONEMOORE, 2007).

A dinastia Han (206 a.C.-220 d.C.) testemunhou uma síntese de confucionismo, legalismo e cosmologia yin-yang. Mas a era foi notabilíssima pela formação do sistema burocrático imperial chinês que dirigiu o país até o século XX com homens formados de acordo com as virtudes confucionistas.

No que se refere ao divino, no pensamento confucionista, a expressão do Supremo é o próprio "Céu” (Tian). Antes de Confúcio, nas dinastias Shang e Zhou, embora os altos deuses - o Senhor das Alturas (Shang Ti) e Tian - fossem concebidos em termos antropomórficos, eles raramente eram inquiridos nas adivinhações, por serem considerados demasiado distantes. O entendimento de Confúcio sobre o Céu era um tanto diferente, falava do Céu como a ordem moral que sustenta o cosmo (OLDSTONE-MOORE, 2007).

Estava convencido de que, embora não fosse pessoalmente bem-sucedido em sua missão de tornar a virtude a base do governo, estava fazendo a vontade 
do Céu, que se manifestava no Mandato celestial concedido ao imperador terrestre ou dele retirado. Na China imperial, apenas o imperador, conhecido como o Filho do Céu, podia realizar atos de culto ao Céu. Isso demonstrava sua autoridade, subscrita pelo Mandato, o que lhe dava um papel essencial como mediador entre o Céu e a Terra.

Os escritos confucionistas são de grande importância para a tradição chinesa. A preocupação dominante do cânone confucionista, que se compõe dos "Seis Clássicos" e dos "Quatro Livros", é a harmonia na ordem social. Confúcio via-se não como criador, mas como mediador dos reis sábios da Antiguidade. $A$ sabedoria desses reis se tornava acessível, sobretudo, através do estudo de seis textos clássicos: Livro das Mutações ( / Ching), Clássico da História, Clássico da Poesia, Anais da Primavera e do Outono, Livro dos Ritos e o Clássico da Música, pedido.

Acredita que ele redigiu os Anais da Primavera e do Outono e um comentário sobre o I Ching e organizado outros livros. De acordo com especialistas modernos, esses textos foram reunidos durante toda a dinastia Zhou (1050 A.C. - 256), e o Clássico da História talvez até antes (OLDSTONE-MOORE, 2007).

Confúcio extraiu lições morais e exemplos de bom governo do Clássico daHistória e dos Anais. Afirmava que para ser uma "pessoa superior", culta, é precisoestar impregnado de música, poesia, cosmologia, adivinhação e etiqueta, tal comoapresentados nos outros clássicos.

Suas prescrições para uma sociedade ideal estão preservadas em Os Anacletos, um registro de seus ditos feito por seus alunos. Nessa obra demonstra como os ritos (II) dos primeiros governantes chineses - desde cerimônias do Estado até etiqueta - fornecem um padrão para a interação humana adequada enatural. Os três outros livros, Mêncio, Grande aprendizado e Doutrina do meio, também descrevem modos de obter um governo virtuoso e uma sociedade harmoniosa. Todos esses textos confucionistas estão escritos na refinada e concisa linguagem do chinês clássico, que deu origem a uma tradição de comentários destinados a elucidar seu significado (OLDSTONE-MOORE, 2007). 


\section{REFERÊNCIAS}

AL-KARAM, Amin Abdel Rahman. A unicidade de Deus e Mohamad (a paz esteja com ele), na Bíblia Sagrada. São Bernardo do Campo: Provo Ed., 2000.

ARMOND, Edgard. Religiões e filosofias. São Paulo: Aliança, 1999.

BESEN, José Artulino. 0 universo religioso: as grandes religiões e tendências religiosas atuais. São Paulo: Ed. Mundo e Missão, 2005.

FELLER, Vitor Galdino. O sentido da salvação: Jesus e as religiões. São Paulo: Paulus, 2005.

GIL, Antônio Carlos. Métodos e técnicas de pesquisa social. São Paulo: Atlas, 1994.

HAGUETTE, Teresa Maria Frota. Metodologias qualitativas na sociologia. 5. ed. Petrópolis: Vozes, 1997.

ISBELLE, Sami Armed. O Estado islâmico e sua organização: sistema político, sistema econômico, sistema jurídico, sistema penal, conceito de Jihad. Rio de Janeiro: Qualitymark, 2007.

LAKATOS, Eva Maria; MARCONI, Marina de Andrade. Fundamentos de metodologia científica. 3. ed. rev. e ampl. São Paulo: Atlas, 1996.

MARQUES, Leonardo Arantes. História das religiões: e a dialética do sagrado. São Paulo: Madras, 2005.

MIRANDA, Mario de França. Inculturação da fé: uma abordagem teológica. São Paulo: Edições Loyola, 2001.

MOHAMAD, Aminuddin. Mohamad: o mensageiro de Deus. São Paulo: Assembléia Mundial da Juventude Islâmica. 1989.

OLDSTONE-MOORE, Jennifer. Tradições chinesas. In: COOGAN, Michael D. Religiões: história, tradições e fundamentos das principais crenças religiosas. São Paulo: Publifolha, 2007.

OLIVEIRA, Paulo Eduardo. Para Compreender o Islã e os Muçulmanos. Rio de Janeiro: Heresis, 2001.

PIKAZA, Xabier. Violência e diálogo das religiões: um projeto de paz. São Paulo: Paulinas, 2008.

RATZINGER, Joseph. Natureza e missão da teologia. Petrópolis: Vozes, 2008. 
SINNER, Rudolf von. Caminhos do Ecumenismo no Brasil: História, Teologia, Pastoral, [2008]. Disponível em:

$<$ http://www.itf.org.br/index.php?pg=conteudo\&revistaid=6\&fasciculoid=101\&sum arioid=1498>. Acesso em: 25 set. 2008.

STOFFEL, Pe. José Carlos. Ecos da IX Assembléia do CMI. In:WOLFF, Elias. Exercitando a cooperação. Florianópolis, ITESC, 2006.

TEIXEIRA, Faustino et al. Ecumenismo e diálogo inter-religioso: a arte do possível. São Paulo: Santuário, 2008.

TERRIN, Aldo Natale. Introdução ao estudo comparado das religiões. São Paulo: Paulinas, 2003.

VIGIL, José Maria. Teologia do pluralismo religioso: para uma releitura pluralista do cristianismo. São Paulo: Paulus, 2006.

WOLFF, Elias. A unidade da Igreja: ensaio de eclesiologia ecumênica. São Paulo: Paulus, 2007.

. Caminhos do ecumenismo no Brasil: história, teologia, pastoral. SãoPaulo: Paulus, 2002.

. Ministros do diálogo: o diálogo ecumênico inter-religioso na formaçãopresbiteral. São Paulo: Paulus, 2004.

. (Org.) Exercitando a cooperação. Florianópolis, ITESC, 2006. 